\title{
A Review of the Biofuel Yield in Hydrothermal Liquefaction of Different Microalgae
}

\author{
Wenhan Song, Shuzhong Wang* and Yang Guo \\ Key Laboratory of Thermo-Fluid Science and Engineering, Ministry of Education, School of Energy \\ and Power Engineering, Xi'an Jiaotong University, Xi'an, Shaanxi, China. \\ *email: swh8648@163.com
}

Keywords: Microalgae; Biofuel; Hydrothermal liquefaction.

Abstract. Among various biomass, microalgae has unique advantages such as fast growing, high efficient photosynthesis, no competition with crops etc. Hydrothermal liquefaction (HTL) is a potential technology for converting microalgae biomass into biofuel, with merits including higher biofuel yield than other methods and lower energy consumption etc. A review of the biofuel yield by HTL of different microalgae is presented here, summarizing the past research about the highest biofuel yield and corresponding conditions for various microalgae. Finally, based on the literatures above-mentioned, future directions in this field are suggested.

\section{Introduction}

\section{A brief introduction of biofuel}

With the development of world economy, more and more fuel is desired. However, traditional fossil fuels are non-renewable resource, pollute the environment and produce many green gases during combustion. Thus, searching an environmentally-friendly and renewable substitution for fossil fuels is necessary. Biofuel is environmentally-friendly, renewable and has excellent combustion performance. Microalgae has properties of short cultivation cycle, high photosynthetic efficiency, high biofuel yield, good quality of biofuel, which is considered a promising substitution for addressing the energy crisis and environmental issues associated with fossil fuel use [1], so microalgae-based biofuel has great potential applications.

\section{Hydrothermal liquefaction reaction}

There are many methods for converting microalgae to biofuel, including pyrolysis [2], transesterification of lipids [3] and hydrothermal liquefaction. Hydrothermal liquefaction (HTL) is considered as the most promising method. HTL is defined as an reaction process by physical-chemical change under the high-temperature and high-pressure water. It has a large number of advantages such as higher energy efficiency, excellent solubility of lower polarity organic molecules [4] and no phase-changing heat dissipation. Moreover, it can convert proteins and polysaccharides from feedstock into lipids, increasing the biofuel yield [5]. So HTL technology can be applied in all microalgae. And it also can improve the recycling of nitrogen, phosphorus, iron et al [6]. In all, HTL has wide applicability, higher biofuel yield and energy efficiency, which has potential development prospects.

The research on HTL of microalgae started in 1994, from Dote et al [7]. With more and more desire of renewable energy, more researchers has focus on it. They performed HTL of different microalgae and obtained the relations between microalgae and reaction parameters. 


\section{HTLs of different microalgae species}

At present, the research on HTL of microalgae primarily was focused on Spirulina, Chlorella, Nannochloropsis, Dunaliella and others such as Desmodesmus, Scenedesmus and Phaeodactylum etc.

\section{Spirulina}

Spirulina is a kind of common microalgae with high proteins and carbohydrates [8], which is often considered as healthy food boosting the body's defenses. The research is shown in Fig.1. Jena et al [8] provided a comparison of Thermochemical Liquefaction (TCL) and slow pyrolysis processes for producing biofuel from algae, indicating that the highest biofuel yield can reach $40.7 \%$ and the higher heating value (HHV) was $34.21 \mathrm{MJ} / \mathrm{kg}$ at $350{ }^{\circ} \mathrm{C}, 60 \mathrm{~min}$ and $20 \%$ solid concentration. In addition, he [9] investigated the optimum TCL operating conditions for biofuel from Spirulina at 200-380 ${ }^{\circ} \mathrm{C}$, 0-120 min, and gained the highest biocrude yield of $39.9 \%$ at $350{ }^{\circ} \mathrm{C}, 60 \mathrm{~min}$ and $20 \%$ solids concentration. HTL of Spirulina with catalysts was also studied [10] and the highest biofuel yield was $51.6 \%$ at $350{ }^{\circ} \mathrm{C}, 60 \mathrm{~min}, 20 \%$ solid concentration and with $5 \% \mathrm{Na}_{2} \mathrm{CO}_{3}$. Vardon et al [11] explored the influence of wastewater feedstock composition on HTL biofuel properties and physico-chemical characteristics at $300{ }^{\circ} \mathrm{C}, 10-12 \mathrm{MPa}, 30$ min reaction time and $20 \%$ solid concentration and finally obtained the highest biofuel yield for Spirulina was $32.6 \%$, whose HHV was $33.2 \mathrm{MJ} / \mathrm{kg}$. Moreover, he [12] compared HTL (300 ${ }^{\circ} \mathrm{C}$ and 10-12 MPa) with slow pyrolysis, and the highest biofuel yield for HTL was $31 \%$. Toor et al [13] performed HTL of Nannochloropsis salina and Spirulina platensis at subcritical and supercritical water conditions $\left(220-375{ }^{\circ} \mathrm{C}, 20-255\right.$ bar) and found that the optimal HTL condition for Spirulina appeared at $310^{\circ} \mathrm{C}, 120 \mathrm{~min}, 25 \%$ solid concentration and $11.5 \mathrm{MPa}$, when the highest biofuel yield was 38\%. From Fig.1, we found that appropriate temperature for high biofuel yield is between $300{ }^{\circ} \mathrm{C}$ and $350{ }^{\circ} \mathrm{C}$, time is about $60 \mathrm{~min}$ and solid concentration is about $20 \%$, also $\mathrm{Na}_{2} \mathrm{CO}_{3}$ as a catalyst for HTL of Spirulina.

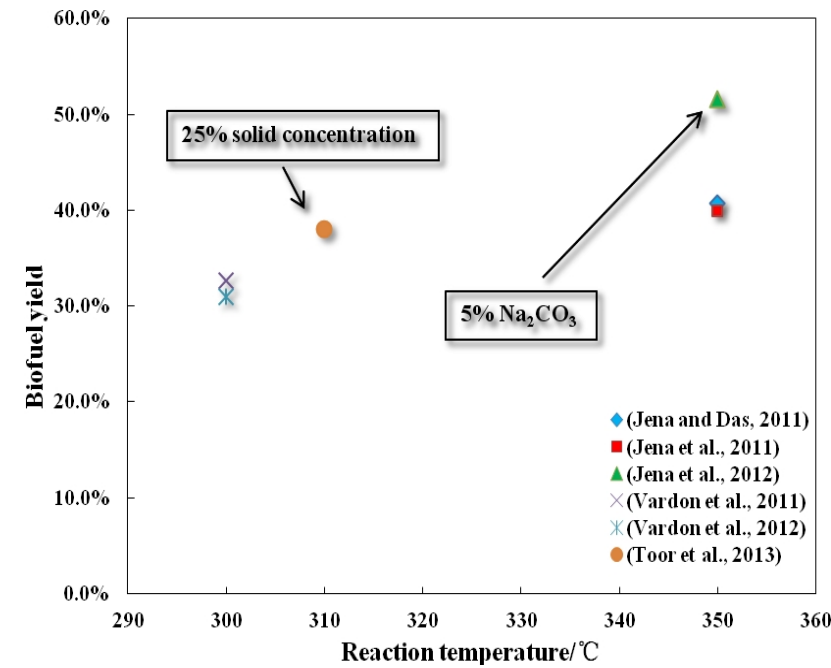

Fig.1 Research about Spirulina

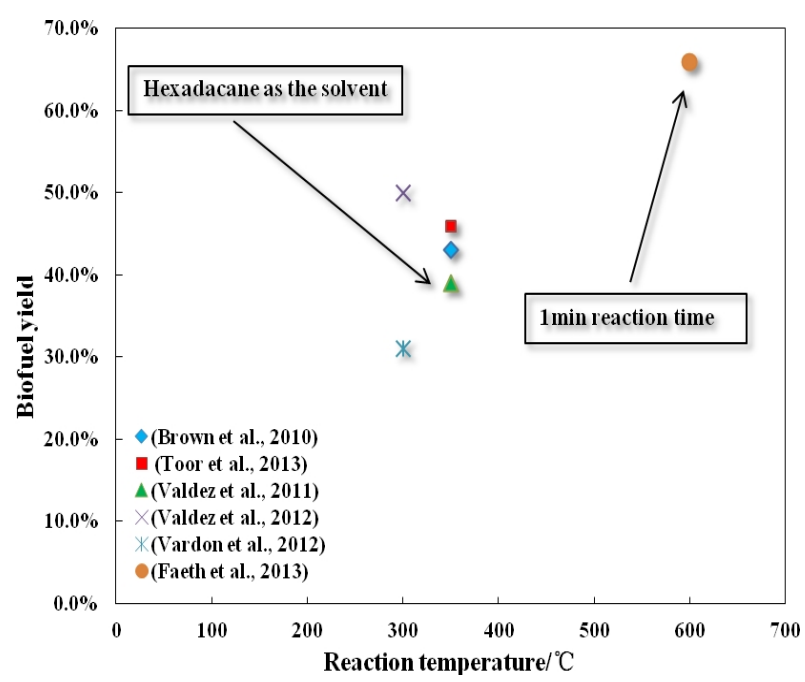

Fig.2 Research about Nannochloropsis

\section{Nannochloropsis}

Nannochloropsis sp. is a marine algae with high-lipid content [14]. There were many studies about it, shown in Fig. 2. Brown et al [15] converted the Nannochloropsis sp. into biofuel via HTL from 200 to $500{ }^{\circ} \mathrm{C}$ with $60 \mathrm{~min}$ and obtained the highest biofuel yield was $43 \%$ at $350{ }^{\circ} \mathrm{C}, 5 \%$ solid concentration, with the $\mathrm{HHV}$ of $39 \mathrm{MJ} / \mathrm{kg}$. Toor et al [13] gained the highest biofuel yield for Nannochloropsis salina in HTL was $46 \%$ at $350{ }^{\circ} \mathrm{C}, 30 \mathrm{~min}, 25 \%$ solid concentration and $17.5 \mathrm{MPa}$. Valdez et al [16] performed HTL of Nannochloropsis sp. at $350{ }^{\circ} \mathrm{C}, 60 \mathrm{~min}$ and $20 \%$ solid concentration by analyzing products and finally he found that the highest biofuel yield was $39 \pm 3 \%$ at hexadecane as the solvent. Also he [17] investigated HTL of Nannochloropsis sp. at $250-400{ }^{\circ} \mathrm{C}, 10-90 \mathrm{~min}$, water densities 
$(0.3-0.5 \mathrm{~g} / \mathrm{mL})$ and biomass loadings $(5-35 \%)$ and gained the highest biofuel yield was $50 \%$ at $300{ }^{\circ} \mathrm{C}$, $10 \mathrm{~min}$ and $15 \%$ solid concentration. Faeth et al[5] studied the fast HTL of Nannochloropsis sp. at 1, 3, and $5 \mathrm{~min}$ and $300-600{ }^{\circ} \mathrm{C}$ and he found that the highest biofuel yield can reach $66 \pm 11 \%$ at $600{ }^{\circ} \mathrm{C}, 1$ min reaction time and $15 \%$ solid concentration. From Fig.2, it is shown that appropriate temperature is between $300{ }^{\circ} \mathrm{C}$ and $350{ }^{\circ} \mathrm{C}$, time range is 30-60 min (except fast HTL technology) and solid concentration is $15-20 \%$, also hexadecane was active as the solvent for HTL of Nannochloropsis.

\section{Chlorella}

Chlorella is a green unicellular alga with low-lipid high-protein content, found in both fresh and marine waters usually [18] and it is also as food grade material. Guo et al [19] studied the effects of operating conditions on the distributions of carbon and nitrogen in HTL products and found that the highest biofuel yield was $39.4 \%$ at $280{ }^{\circ} \mathrm{C}, 120 \mathrm{~min}$ and $20 \%$ solid concentration. And he [20] investigated the effects of key operating parameters (reaction temperature, reaction time and initial pressure) on the oil product yields and found that the highest refined oil yield was $39.4 \% \pm 1.2 \%$ of the total dry mass of algal feedstock, achieved under that condition of $280{ }^{\circ} \mathrm{C}$ reaction temperature and 120 min reaction time. Miao et al [21] compared the two-step sequential hydrothermal liquefaction (SEQHTL) with direct hydrothermal liquefaction (DHTL) and studied the effects of parameters (reaction temperature, reaction time and biomass/water ratio) on the product distribution. The result showed that the biofuel yield can be over $30 \%$ at $240{ }^{\circ} \mathrm{C}, 20 \mathrm{~min}$ and $1: 9$ biomass/water ratio by SEQHTL after considering the operation cost.

\section{Dunaliella}

Dunaliella has proteins (32\%), lipids (22\%) and carbohydrate (20\%) [22]. Zou et al [22] converted Dunaliella into biofuel through a sub- and supercritical water liquefaction process and studied the effects of parameters on the yields of the products. The results showed that the maximum biofuel yield was $36.9 \%$ at $360{ }^{\circ} \mathrm{C}, 30 \mathrm{~min}$ and a feedstock ratio of materials to water of 1:10. Zou et al [23] investigated HTL of Dunaliella under certain catalyst and obtained the maximum biofuel yield of $25.8 \%$ at $360{ }^{\circ} \mathrm{C}, 50 \mathrm{~min}$ using $5 \% \mathrm{Na}_{2} \mathrm{CO}_{3}$ as a catalyst. Zou et al [24] studied TCL of Dunaliella in ethylene glycol acidified with $\mathrm{H}_{2} \mathrm{SO}_{4}$ as a catalyst and set up the mathematical model by a central composite rotatable design (CCRD) and response surface analysis (RSA). Finally, he obtained the highest liquefaction yield of Dunaliella was $97.05 \%$ under the optimized condition of $170{ }^{\circ} \mathrm{C}, 33 \mathrm{~min}$ and $2.4 \%$ $\mathrm{H}_{2} \mathrm{SO}_{4}$ added. Minova et al [25] studied the effects of reaction parameters on the biofuel yield and obtained the highest biofuel yield was $43.8 \%$ at $300{ }^{\circ} \mathrm{C}, 5 \mathrm{~min}, 25 \%$ solid concentration and no $\mathrm{Na}_{2} \mathrm{CO}_{3}$, differed from Zou [23], maybe due to difference of feedstock or processing. Moreover, Yang et al [26] investigated HTL of Dunaliella salina over solid acid catalyst and obtained the highest biofuel yield of Dunaliella was $72.0 \%$ under the condition of $200{ }^{\circ} \mathrm{C}$, initial $\mathrm{H}_{2}$ pressure $2.0 \mathrm{MPa}, 60 \mathrm{~min}, 10 \%$ solid concentration and Ni/REHY as the catalyst.

\section{Others}

There are few research about other microalgae. Alba et al [27] converted Desmodesmus into biofuel by hydrothermal treatment (HTT) technology and the maximum biofuel yield (49\%) was obtained at $375{ }^{\circ} \mathrm{C}$ and $5 \mathrm{~min}$. Vardon et al [12] obtained the conclusion that raw Scenedesmus had the highest yield of HTL bio-oil (45\%) and about defatted Scenedesmus (36\%) during the experiments of comparing HTL with slow pyrolysis. Christensen et al [28] processed Phaeodactylum by HTL in order to assess the influence of reaction temperature and reaction time on the product and elemental distribution and found that the highest bio-oil yield can reach $39 \%$ under the condition of $350{ }^{\circ} \mathrm{C}$ and $15 \mathrm{~min}$. Tian et al [29] focused on the HTL of harvested algae from Dianchi in China and obtained the highest biofuel yield $(18.4 \%)$ at $300{ }^{\circ} \mathrm{C}, 60 \mathrm{~min}$ and $20 \%$ solid concentration. Hognon et al [30] found 
that the highest biofuel yield was $71 \%$ at $230{ }^{\circ} \mathrm{C}, 60 \mathrm{~min}$ and $14 \%$ solid concentration for Chlamydomonas reinhardtii.

\section{Conclusions and future directions}

For microalgae feedstock, hydrothermal liquefaction is a very potential technology for producing biofuel. As far as we're aware, it can offer efficient conversion from microalgae to biofuel, avoid water phase-changing heat dissipation and improve the recycling process of nutrients and metal elements, in favour of follow-up use of them.

Microalgae is composed of proteins, polysaccharides and lipids primarily. Different microalgae differ from percentage compositions of these three substances. Although some microalgae are low-lipid but high-protein, the biofuel yield is not always lower than high-lipid species due to outstanding advantages of HTL above-mentioned. Therefore, different microalgae species may result in different optimal reaction parameters, biofuel yields, higher heating values (HHV) and distributions of products. The summary of HTL of different microalgae can provide a research overview for further investigation in the very potential field with rapid development.

In the future, the research about the cell structure of microalgae need to be studied deeper. Various microalgae produce different compositions of biofuel and aqueous products, which may be necessary to quantify for follow-up separation and processing. Also, the reaction kinetic research for feedstock and some intermediate products need to be devoted to the field to explore the reaction mechanism of HTL completely.

\section{Acknowledgements}

This research was supported by China Postdoctoral Science Foundation (126540), Jiangsu Province Natural Science Foundation of China (BK20140406), National Natural Science Foundation (51406146) and Shaanxi Province Natural Science Foundation of China (2014JQ2081).

\section{References}

[1] A. Demirbas, Biomass resource facilities and biomass conversion processing for fuels and chemicals, Energy Conversion and Management, 42 (2001) 1357-1378.

[2] S.P. Zou, Y.L. Wu, M.D. Yang, C. Li, J.M. Tong, Pyrolysis characteristics and kinetics of the marine microalgae Dunaliella tertiolecta using thermogravimetric analyzer, Bioresource Technology, 101 (2010a) 359-365.

[3] H. Xu, X. Miao, Q. Wu, High quality biodiesel production from a microalga Chlorella protothecoides by heterotrophic growth in fermenters, Journal of Biotechnology, 126 (2006) 499-507.

[4] N. Akiya, P. E. Savage, Roles of Water for Chemical Reactions in High-Temperature Water, Chemical Reviews. 102 (2002) 2725-2750.

[5] J. L. Faeth, P. J. Valdez, P. E. Savage, Fast Hydrothermal Liquefaction of Nannochloropsis sp. To Produce Biocrude, Energy \& Fuels, 27 (2013) 1391-1398.

[6] P. G. Duan, P. E. Savage, Hydrothermal Liquefaction of a Microalga with Heterogeneous Catalysts, Industrial \& Engineering Chemistry Research, 50 (2010) 52-61.

[7] Y. Dote, S. Sawayama, S. Inoue, T. Minowa, S.-Y. Yokoyama, Recovery of liquid fuel from hydrocarbon-rich microalgae by thermochemical liquefaction, Fuel, 73 (1994) 1855-1857.

[8] U. Jena, K. C. Das, Comparative Evaluation of Thermochemical Liquefaction and Pyrolysis for Bio-Oil Production from Microalgae, Energy \& Fuels, 25 (2011) 5472-5482. 
[9] U. Jena, K. C. Das, J. R. Kastner, Effect of operating conditions of thermochemical liquefaction on biocrude production from Spirulina platensis, Bioresource Technology, 102 (2011) 6221-6229.

[10] U. Jena, K. C. Das, J. R. Kastner, Comparison of the effects of Na2CO3, Ca3(PO4)2, and NiO catalysts on the thermochemical liquefaction of microalga Spirulina platensis, Applied Energy, 98 (2012) 368-375.

[11] D. R. Vardon, B. K. Sharma, J. Scott, Y.Guo, Z. Wang, L. Schideman, Y. Zhang, T. J. Strathmann, Chemical properties of biocrude oil from the hydrothermal liquefaction of Spirulina algae, swine manure, and digested anaerobic sludge, Bioresource Technology, 102 (2011) 8295-8303.

[12] D. R. Vardon, B. K. Sharma, G. V. Blazina, K. Rajagopalan, T. J. Strathmann, Thermochemical conversion of raw and defatted algal biomass via hydrothermal liquefaction and slow pyrolysis, Bioresource Technology, 109 (2012) 178-187.

[13] S. S. Toor, H. Reddy, S. Deng, J. Hoffmann, D. Spangsmark, L. B. Madsen, J. B. Holm-Nielsen, L. A. Rosendahl, Hydrothermal liquefaction of Spirulina and Nannochloropsis salina under subcritical and supercritical water conditions, Bioresource Technology, 131 (2013) 413-419.

[14] L. A. Gouveia, C. Oliveira, Microalgae as a raw material for biofuels production, Journal of Industrial Microbiology \& Biotechnology, 36 (2009) 269-274.

[15] T. M. Brown, P. G, Duan, P. E. Savage, Hydrothermal Liquefaction and Gasification of Nannochloropsis sp, Energy \& Fuels. 24 (2010) 3639-3646.

[16] P. J. Valdez, J. G. Dickinson, P. E. Savage, Characterization of Product Fractions from Hydrothermal Liquefaction of Nannochloropsis sp. and the Influence of Solvents, Energy \& Fuels, 25 (2011) 3235-3243.

[17] P. J. Valdez, M. C.Nelson, H. Y. Wang, X. N. Lin, P. E. Savage, Hydrothermal liquefaction of Nannochloropsis sp.: Systematic study of process variables and analysis of the product fractions, Biomass and Bioenergy, 46 (2012) 317-331.

[18] E.W. Becker, Cambridge Studies in Biotechnology, Cambridge University Press, New York,1994, pp.10011-4211.

[19] Y.Guo, Y. Zhang, L. Schideman, T. Funk, Z. Wang, Distributions of carbon and nitrogen in the products from hydrothermal liquefaction of low-lipid microalgae, Energy \& Environmental Science, 4 (2011) 4587-4595.

[20] Y.Guo, Y. Zhang, L. Schideman, T. L. Funk, Hydrothermal liquefaction of low lipid content microalgae into bio-crude oil, American Society of Agricultural and Biological Engineers, 54 (2010) 239-246.

[21] C. Miao, M. Chakraborty, S.L. Chen, Impact of reaction conditions on the simultaneous production of polysaccharides and bio-oil from heterotrophically grown Chlorella sorokiniana by a unique sequential hydrothermal liquefaction process, Bioresource Technology, 110 (2012) 617-627.

[22] S.P. Zou, Y.L. Wu, M.D. Yang, C. Li, J.M. Tong, Bio-oil production from sub- and supercritical water liquefaction of microalgae Dunaliella tertiolecta and related properties, Energy \& Environmental Science, 3 (2010) 1073-1078.

[23] S.P. Zou, Y.L. Wu, M.D. Yang, I. Kaleem, C. Li, J.M. Tong, Production and characterization of bio-oil from hydrothermal liquefaction of microalgae Dunaliella tertiolecta cake, Energy, 35 (2010b) 5406-5411.

[24] S.P. Zou, Y.L. Wu, M.D. Yang, C. Li, J.M. Tong, Thermochemical Catalytic Liquefaction of the Marine Microalgae Dunaliella tertiolecta and Characterization of Bio-oils, Energy \& Fuels, 23 (2009) 3753-3758. 
[25] T. Minowa, S.-Y. Yokoyama, M. Kishimoto, T. Okakura, Oil production from algal cells of Dunaliella tertiolecta by direct thermochemical liquefaction, Fuel, 74 (1995) 1735-1738.

[26] C. Yang, L. Jia, C. Chen, G. Liu, W. Fang, Bio-oil from hydro-liquefaction of Dunaliella salina over Ni/REHY catalyst, Bioresource Technology, 102 (2011) 4580-4584.

[27] G. Alba, L, C. Torri, C. Samor, J. van der Spek, D. Fabbri, S. R. A. Kersten, D. W. F. Brilman, Hydrothermal Treatment (HTT) of Microalgae: Evaluation of the Process As Conversion Method in an Algae Biorefinery Concept. Energy \& Fuels, 26 (2011) 642-657.

[28] P. S. Christensen, G. Peng, F. Vogel, B. B. Iversen, Hydrothermal Liquefaction of the Microalgae Phaeodactylum tricornutum: Impact of Reaction Conditions on Product and Elemental Distribution, Energy \& Fuels. 28 (2014) 5792-5803.

[29] C. Y. Tian, Z. D. Liu, Y. H. Zhang, B. M. Li, W. Cao, H. F. Lu, N. Duan, L. Zhang, T. T. Zhang, Hydrothermal liquefaction of harvested high-ash low-lipid algal biomass from Dianchi Lake: Effects of operational parameters and relations of products, Bioresource Technology, 184 (2015) 336-343.

[30] C. Hognon, F. Delrue, J. Texier, M. Grateau, S. Thiery, H. Miller, A. Roubaud, Comparison of pyrolysis and hydrothermal liquefaction of Chlamyclomonas reinharcltii. Growth studies on the recovered hydrothermal aqueous phase, Biomass \& Bioenergy, 73 (2015) 23-31. 